Revista de la red interuniversitaria de estudios sobre las literaturas rioplatenses contemporáneas en Francia

$13 \mid 2015$

Nuevas experiencias editoriales y literaturas

contemporáneas

\title{
Tipos móviles : las editoriales también nacen pequeñas
}

Mariano García

\section{OpenEdition}

Journals

Edición electrónica

URL: http://journals.openedition.org/lirico/2138

DOI: 10.4000/lirico.2138

ISSN: 2262-8339

Editor

Réseau interuniversitaire d'étude des littératures contemporaines du Río de la Plata

Referencia electrónica

Mariano García, «Tipos móviles : las editoriales también nacen pequeñas », Cuadernos LIRICO [En línea], 13 | 2015, Puesto en línea el 15 diciembre 2015, consultado el 21 abril 2019. URL : http:// journals.openedition.org/lirico/2138; DOI : 10.4000/lirico.2138

Este documento fue generado automáticamente el 21 abril 2019.

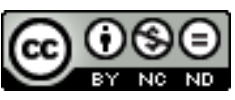

Cuadernos LIRICO está distribuido bajo una Licencia Creative Commons Atribución-NoComercialSinDerivar 4.0 Internacional. 


\title{
Tipos móviles : las editoriales también nacen pequeñas
}

\author{
Mariano García
}

1 Los temores apocalípticos de fin de milenio parecieron encontrar su confirmación fatalista de "profecía autocumplida" con la crisis que estalló en la Argentina en diciembre de 2001 y que, como suele ocurrir en estos casos, dio una estocada mortal a un sector no precisamente privilegiado por las sucesivas agendas políticas de nuestro país ; vale decir, la cultura. Sin embargo, para tratarse de una nación (o por lo menos de una ciudad, Buenos Aires, con pretensiones metonímicas de representar al país entero) conocida por sus numerosas librerías y sofisticados lectores, la crisis del mercado del libro no fue tan sorpresiva ni tan nueva.

2 A los miedos espectrales suscitados por la visible competencia del libro digital, miedos que no casualmente desata el "maestro del terror" Stephen King al anunciar la publicación de su última novela exclusivamente por internet en agosto de 2000, se suma una odisea local que viene de algo más lejos : la Cámara Argentina del Libro anuncia en diciembre de 2001 una caída del $50 \%$ de las ventas globales desde 1999. En julio de 2001 se había promulgado finalmente -con treinta años de retraso- una esperada ley del libro para fomento del sector, que garantizaba partidas para el abastecimiento de materiales bibliográficos, pero que sufre el veto de diversos artículos por parte del presidente De la Rúa, relativos a exenciones impositivas y beneficios tributarios (Pomeraniec 37). Ya una agorera nota en el diario Clarín del 2 de septiembre de 2001 se preguntaba en su título “ ¿ La novela argentina está en crisis?", pasando a constatar la escasez de ediciones y reediciones locales. En medio de la desazón de editores y libreros se produce la hecatombe de diciembre (aunque "las góndolas de libros de Musimundo permanecieron inmunes a los saqueadores", según el copete del suplemento de cultura de Clarín del 12 de enero de 2002) y el infausto "corralito", a partir del cual se suspende la importación de libros, que incluye las novedades de algunos autores argentinos editados afuera, como ocurre con el Tratado de las sensaciones de Arturo Carrera, En otro orden de cosas de Fogwill, Mantra de Rodrigo Fresán, Cumpleaños de César Aira o Leyenda de Diana Bellessi (Molina 2). La edición de abril de 2002 de la Feria del Libro amenaza con suspenderse a causa de los 
precios delirantes de los libros. Las ventas se concentran principalmente en los saldos, las ofertas y las liquidaciones. Frente a la imposibilidad de las editoriales locales para pagar derechos y costear ediciones de obras completas, los herederos o derechohabientes de Macedonio Fernández o Silvina Ocampo, por poner dos ejemplos, buscan ofertas del extranjero (Pérez 2002) señalando una dispersión del patrimonio que resume otro titular impregnado del pesimismo general que se respira : "El libro en coma" (Clarín, 12 de enero de 2002). Frente a un panorama tan desolado, no es de extrañar que las reflexiones de los intelectuales apuntaran, sin demasiado optimismo, a un cuestionamiento acerca de nuestra identidad y de nuestro malogrado proyecto de ilustración.

3 Sin embargo, expertos involuntarios en naufragios como somos, la crisis económica impulsó a los editores a desplegar una serie de estrategias que fueron modificando, a lo largo de esa primera década del siglo xxI, el panorama editorial local tal como se lo conocía hasta entonces. Por un lado, algunos nombres que combinan prestigio con solvencia comercial pasan a un segundo plano, como la editorial Emecé, comprada y absorbida en 2000 por Planeta, drásticamente mermado su plantel y progresivamente reducida a sus "marcas" más características, vale decir a los nombres de Borges, Bioy y Silvina Ocampo. También se verá obligada a limitar poco a poco la publicación de autores contemporáneos, como es entre otros el caso de César Aira, autor impulsado por Emecé hasta que se descontinúa su presencia a partir de La villa (2001), título que aborda precisamente algunos aspectos de la mencionada crisis (Chejfec 2002). Por otro lado, se multiplican llamativamente las editoriales chicas, cada cual con proyectos específicos, un catálogo discreto en principio y en algunos casos con un interés marcado en el diseño del libro como objeto. Así, irán apareciendo Interzona, El cuenco de plata, Entropía, Eterna cadencia, La compañía, Las cuarenta, Caja Negra, Katz, Mar dulce, Mansalva, así como la muy original Eloísa Cartonera y las ediciones de Belleza y Felicidad, que ofrecen algo así como ejemplares de colección ya sea por las características artesanales de su armado (tapas de cartón reciclado pintadas a mano) o por tratarse de ediciones limitadas de textos breves, a la manera de plaquettes, en un muy oportuno reflejo material de las condiciones de precariedad presentes.

4 Sin embargo, la dirección a la que apuntaba este mercado no nació directamente condicionada por la crisis, o al menos puede decirse que tuvo un par de precursores significativos. Uno de ellos, la rosarina Beatriz Viterbo, en sus inicios volcada principalmente a la publicación de ensayos académicos -donde los autores o la universidad en que trabajan normalmente financian parte de la edición- y a algunos autores por entonces "marginales" o "emergentes" como Guebel, Bizzio, Chejfec y de nuevo Aira. El otro precursor es la editorial que nos ocupa, Adriana Hidalgo, que propone desde el principio una combinación de ensayo internacional y ficción nacional.

5 Adriana Hidalgo Editora nace en agosto de 1999 formada por su directora homónima y por los editores Edgardo Russo y Fabián Lebenglik, emigrados los tres de la editorial El Ateneo cuando esta cambia de manos y los nuevos dueños deciden retirarse de la edición de libros. Adriana Hidalgo Solá pertenece a la familia que había fundado primero la librería y luego la editorial El Ateneo, en tanto que Lebenglik y Russo fueron allí por quince años los editores de la colección de diccionarios y enciclopedias. Juntos deciden iniciar esta nueva apuesta sumando en el área del diseño al artista plástico Eduardo Stupía (responsable de la maqueta de las tapas) y Pablo Hernández. El lanzamiento, al ritmo de un título por semana, se produce con unos ensayos de Auden, los estudios que Harold Bloom dedicó a los románticos ingleses, más obras como La piel de caballo de 
Ricardo Zelarayán, Los pasos previos de Francisco Urondo, Zama de Antonio di Benedetto, y la "novela" Reina Amelia de la uruguaya Marosa di Giorgio. Al libro original de ensayos de Auden, The Dyer's Hand (1962), la editorial lo dividió en dos volúmenes : El mundo de Shakespeare y La mano del teñidor. El original de Bloom, The Visionary Company (1971), fue presentado en tres tomos. El rótulo genérico del texto de Di Giorgio corre por cuenta de los editores; las características estructurales de este texto no difieren de otros que la autora denomina "poemas" y que responden a la tradición de los poemas en prosa. Vemos pues en estos tres casos, desde los inicios, intervenciones editoriales atentas a la respuesta del mercado.

6 Con respecto a la selección de títulos no ficcionales, si bien los ensayos de Auden y Bloom son, desde luego, ya viejos, constituyen no obstante una novedad en el mercado latinoamericano. En estos tentativos primeros pasos, la editorial apunta a cubrir una laguna de textos extranjeros que no han sido traducidos o que solo circulan en el mercado español. Como lo aclaró Fabián Lebenglik a los cinco meses de inaugurada la editorial, "La idea era comenzar a publicar libros para un público que quiere leer y reflexionar. Durante toda la década del noventa hubo una ausencia total de reflexión y me propuse aportar mi granito de arena para contribuir a que vuelva" (Aznarez 8).

7 En cuanto a la narrativa, se trata de nombres prestigiosos aunque no de circulación masiva y, en el caso de Di Benedetto, un rescate que constituirá uno de los primeros éxitos de la editorial, a la que se le debe en buena medida la nueva visibilidad que este autor obtiene en el canon de nuestras letras, como lo atestigua lo propuesto por Julio Premat (2009). De este modo queda más o menos fijado lo que serán las dos grandes vertientes de este proyecto, enriquecidas paulatinamente con colecciones como la de ficción internacional (que irá ampliando su espectro con traducciones directas de idiomas poco frecuentes como el japonés, el neerlandés, el ruso o el portugués), teatro nacional (Spregelburd, Veronese, Federico León) e internacional (Stoppard, Grass, Bernhard, Fassbinder), ensayos sobre artes plásticas, biografías ; en suma, un proyecto que apunta a la difusión de expresiones relevantes locales, pero que también cuenta con capital para asumir los derechos de obras extranjeras algo más esporádicas en el mercado. ${ }^{1}$

8 Con la crisis por delante, la editorial consigue su primer triunfo de supervivencia frente a la inestable economía argentina gracias al oportuno aterrizaje en el extranjero, acordado desde el principio con Océano, la distribuidora de aquel entonces. Primero Uruguay, luego México y finalmente España serán los países de esta expansión, sostenida por una presencia conspicua en ferias internacionales como la de Guadalajara o Frankfurt. Tras una reestructuración en 2002 en la que Lebenglik queda como único editor, la editorial se afianzará paulatinamente como una propuesta sólida en su campo, y a la vez con suficiente versatilidad como para adaptarse a los sacudones económicos y sus consecuencias (aumento del precio del papel, aumento del valor de los derechos de títulos extranjeros al cambio del peso argentino, trabas a la importación, etc.) así como a los gustos del lector argentino y más en general del lector de habla hispana. Pasada la novedad, la editorial ya no recibe loas unánimes en los suplementos literarios (que también sufrieron transformaciones drásticas en estos años clave) por cada título que saca, sino que debe competir en los espacios de difusión con las propuestas de nuevas editoriales, que son cada vez más numerosas.

Para tratarse de una empresa todavía chica, hay un par de éxitos que jalonan no solo el prestigio de la editorial sino que garantizan su supervivencia gracias a las reediciones del fondo: a varios títulos del ya mentado Di Benedetto y de Giorgio Agamben (Infancia e 
historia es un libro de filosofía que llegó a su quinta edición y que tuvo una entusiasta recepción en la prensa local) se sumarán cuidadas colecciones de antologías (sobre vampiros, fantasmas, licántropos, el cuento policial, la comida en la literatura) y de obra reunida de poetas (Baron Supervielle, Bellessi, Bignozzi, Biagioni, Calveyra, Carrera, Di Giorgio, Kamenszein, Orozco, Urondo) de buen rendimiento comercial. Otros intentos similares no correrán la misma suerte pese a su indudable calidad, como es el caso de la muy original colección sobre el anecdotario de compositores clásicos, que no alcanza los objetivos que suponen estas iniciativas de discreto carácter comercial. Sin embargo las colecciones se multiplican, como lo atestigua la incorporación de una de volúmenes monográficos sobre artistas plásticos y otra de literatura infantil, y el equipo editorial crece.

Mantener el equilibrio entre calidad y finanzas no es tarea sencilla, y la editorial tiene que sacar partido cuando la ocasión se presenta: reeditar un libro sobre Wagner para el aniversario del compositor, publicar de manera independiente el relato "Aballay" de Di Benedetto en ocasión del estreno de la película sobre dicho texto, o bien tener en circulación ejemplares de obras teatrales en cartel o de artistas que expongan en museos o galerías. Asimismo, el acuerdo para publicar al ganador del premio anual que organiza la Biblioteca Nacional apunta a una cierta visibilidad comercial en un país donde no abundan precisamente los premios o estímulos a la literatura. No obstante, la incorporación de algún título del catálogo en programas oficiales de educación representa una venta asegurada. El azar, por su parte, también puede dar una mano importante si a la sazón sale ganador del Nobel un autor "de la casa", como ocurrió con Le Clézio en 2008, hecho que significó un importante espaldarazo para la editorial y que acaso allanara su paso definitivo de una estructura pequeña a una mediana.

11 Si bien es lógico pensar que las grandes editoriales que conocemos hoy también nacieron pequeñas, hay quienes consideran que las editoriales pequeñas seguirán siéndolo por siempre, y que un abismo insondable separa una editorial de carácter comercial de una que apuesta por el Arte, con mayúsculas. Estas consideraciones esencialistas y muy poco matizadas, como tuve la oportunidad de escuchar en un congreso de literatura en la Universidad de Granada (octubre de 2014), ignoran algo que salta a la vista en cualquier economía de libre mercado : el crecimiento debe ser constante. Las formas de garantizar ese crecimiento son muy diversas y a veces implican una ligera traición al espíritu de la marca, si bien eso también conlleva sus riesgos frente a un público que sabe o cree saber lo que le va a ofrecer una editorial en la que confía.

12 La editorial Siruela de España, por ejemplo, comenzó con un catálogo digno de un buscador de tesoros ocultos, y con libros que materialmente se ofrecían como objetos suntuosos, de bibliófilo, pero una vez vendida por su dueño y director, Jacobo Siruela, la editorial se fue desplazando hacia un terreno más realista intentando no perder su identidad, aunque su catálogo está hoy muy lejos de las elecciones exquisitas de sus primeros tiempos, lo mismo que la calidad del soporte. También la editorial Salamandra, que nace en 2000 a partir de lo que era Emecé Editores España, a cargo del argentino Pedro del Carril y de Sigrid Kraus, propone un catálogo más literario que puramente comercial, con formidables éxitos póstumos como Irène Nemirovksy o Sandor Marai, pero también la "bomba" editorial de Harry Potter y paulatinamente más títulos comerciales, vale decir, la misma estrategia que en su momento desplegó la porteña Emecé, en la que convivían alegremente las Literaturas germánicas medievales de Borges con Sidney Sheldon en la colección "grandes novelistas 
13 Sin embargo, a diferencia de lo que ocurría con Emecé, en Salamandra aparece cierta tendencia a ofrecer como artístico lo que muchas veces no lo es. No se trata ya de que convivan una colección comercial con otra puramente literaria, sino de ofrecer de antemano todo junto, respaldado por el renombre del sello. ¿ Se puede hablar entonces de nuevos híbridos a la vez literarios y comerciales? ¿ O sigue y seguirá existiendo siempre el límite entre una y otra modalidad ? ¿ Este límite es el mismo para todos los lectores o varía según países y culturas ? Como mi intención es señalar la evolución en un autor que represente un cambio análogo en las políticas editoriales, será conveniente, para el desarrollo de este trabajo, determinar qué entiendo por escritos de carácter comercial y qué entiendo por literatura puesto que, parafraseando a Agustín de Hipona, todos creemos conocer esa distinción, pero si nos preguntan en qué consiste, ya no resulta tan fácil responder.

Por empezar, habría que aceptar que un libro con intención comercial es el que se propone y consigue vender la mayor cantidad de ejemplares en el menor tiempo posible. Para eso, la tradición anglosajona del best-seller, que es el ámbito en que nació, fue perfeccionando sus herramientas, de manera que esa clase de libros sea reconocible en forma inmediata : una determinada longitud, que normalmente supera las 500 páginas, un título que sea lo bastante descriptivo de lo que se va a leer o que por lo menos permita al lector hacerse una idea específica del producto en el que elige invertir su dinero, a partir de una hipercodificación genérica previa y una publicidad ubicua y aclaratoria; se trata de un libro que vale por sí mismo, más que el autor o que el concepto de "obra"; en él la ambigüedad del mensaje aparece reducida al máximo: "el best-seller dice lo que quiere decir, y lo ofrece como lo que es" (Aira 7); de la mano de esta característica se desprende la siguiente, que es la de cierto saber útil que promueve el libro comercial (por lo general subrayado por el autor, cuando explica el trabajo que le llevó reunir la información para tal tema o las entrevistas que mantuvo) frente a la inutilidad intrínseca de la literatura y sus búsquedas "interiores".

No todos los libros con intención comercial, empero, se amoldan a los criterios estrictos del best-seller. Como mencioné más arriba, un ganador del Nobel o cualquier otro premio prestigioso puede convertirse en un éxito de ventas sin que por ello sus libros se adapten a estos rígidos criterios. Fuera del ámbito anglosajón, y específicamente fuera de la industria estadounidense, donde puede coincidir la calidad literaria con el éxito comercial de un Truman Capote, por ejemplo, hay opciones intermedias. Una de ellas es el policial, fórmula atractiva que además permite cierto coqueteo con la Alta Literatura, si nos atenemos a la gran cantidad de escritores prestigiosos que se volcaron y se siguen volcando a este género. Los temas nacionales pueden concitar también la atención de un gran público que no vive pendiente de la literatura. En nuestro país el tópico de la dictadura militar demostró en esta última década ser un tema de interés sostenido al que respondieron tanto nombres establecidos como autores nóveles, tal como en los noventa tuvo su auge la novela histórica. Por esto mismo, no se hizo esperar la combinación de policial con tema nacional, como el caso de una autora publicada en Adriana Hidalgo, Alicia Plante, que en su "trilogía del agua" compuesta por Una mancha más (2011), Fuera de temporada (2013) y Verde oscuro (2014) lleva a cabo esta incorporación de temas locales a un género de codificación y tradición bien definida.

La autora que voy a considerar, la tandilense Patricia Ratto, presenta una obra distinta pero en la que también recurren, de manera desplazada o alusiva, temas como la dictadura o la guerra de Malvinas. Pequeños hombres blancos (2006), su primera novela, 
aparece en el campo literario ubicándose indirectamente en la genealogía "dialógica" de Manuel Puig ya desde un epígrafe que a simple vista puede descolocar : "Los hechos por venir rara vez proyectan su sombra ante ellos". La frase pertenece a Ivy ComptonBurnett, peculiar autora inglesa que por su uso distintivo del diálogo (Sarraute 1956) fue mencionada por la crítica como precursora de Puig, que sin embargo afirmó no conocerla. Si bien Puig se internó por otros caminos que los señalados por las novelas de aspecto civilizado y fondo turbio de Compton-Burnett, Ratto parece elegir como punto de partida el modelo formalmente menos exigente de esta última, modelo que no se restringe a la palabra de los personajes sino que se permite un discreto narrador en tercera persona cuando los límites del diálogo se vuelven demasiado estrechos, con lo cual la novela se aparta desde el inicio de toda experimentación que pueda resultar excesiva o que ponga a prueba la comprensión del lector. También, muy en la línea de la británica, el marco histórico elegido (la dictadura argentina) no recurre a momentos centrales ni espectaculares sino que privilegia los márgenes y los sobreentendidos, aunque sin la brillantez de Compton-Burnett para las elipsis.

La narración presenta a Gabriela, una profesora de Tandil que consigue trabajo en la escuela de un pueblo de Chubut, José de San Martín. Allí se hará amiga de una colega con la que comparte la casa que les da gratis la escuela, pero también de la dueña del cabaret local, llamado Pichi Huinca según una expresión mapuche de la que el título es la traducción. A su vez, Gabriela comenzará a noviar con el comandante Blanco, pese al clima de persecución que se vive aun en ese pueblo perdido en medio de la nada y pese a que Gabriela demuestra tener una postura contraria a los "milicos". En esta ambigüedad, que humaniza y da verosimilitud a la protagonista, reside el hallazgo la historia. Gabriela será testigo de dos situaciones que por su violencia soterrada se asumen más como metáforas de la dictadura que como hechos históricos puntuales : por un lado, el perro siberiano que un vecino militar regala a Gabriela aparece muerto tras haber mordido al hijo del comisario, pese a la intercesión de Blanco para salvarlo. Por otro, una alumna de Gabriela, jovencita de familia mapuche, es víctima del secuestro de su hijo recién nacido, del que le hacen creer que nació muerto. Estos y algunos detalles más, presentados en sordina, se ven desdibujados, desrealizados por las versiones e intervenciones de los distintos personajes.

En una concesión sentimental, la prostituta del lugar tiene un gran corazón (“... es una de las personas más auténticas en este maldito pueblo", dice de ella Gabriela, 155) y capta enseguida que Gabriela es una "buena chica", lo mismo que la abuela mapuche de su alumna. Las mujeres, marginadas por definición en una sociedad previsiblemente violenta y machista, se refugian en la "transparencia de los sentimientos", que pueden incluso revelar una profundidad profética. Así, la tirada de cartas que Adela, la Pichi, le hace a Gabriela (157-160) no solo permite introducir lo que será el futuro de Gabriela fuera del marco textual, sino que establece de manera inconfundible el referente de la gitana que le tira las cartas a Juan Carlos en Boquitas pintadas. Entre un juego más o menos sutil con los lugares comunes, donde no parece que se usen con el distanciamiento crítico de Puig sino que buscan más bien establecer una empatía directa y rápida con el lector, y cierta voluntad didáctica o aclaratoria que borronea con trazo grueso las sutilezas más o menos conseguidas del texto (" $¿$ Sabés que en el fondo tu razonamiento se parece bastante al de ellos, al de los milicos ? [...] Dejar que todo siga como está es quizá la peor violencia de todas [...] porque de esa manera todos somos cómplices", 150-1) persiste una ambigüedad que, junto con una manera atractiva de presentar a los personajes a través de su lengua, 
plantean un debut razonablemente satisfactorio, muy festejado en la contratapa por el conciudadano Jorge Di Paola, con cuya estética este texto no guarda relación alguna. Ubicándose en una temática actual pero no original e invocando un modelo experimental del que rescata los aspectos más inmediatamente legibles y sentimentalmente asimilables, Ratto se da a conocer con una obra que se centra en la construcción de personajes al borde del estereotipo y cuya protagonista está destinada a producir la identificación con un lector algo más curioso que el de un best-seller convencional pero no tanto como el de títulos más extremos de Nicolás Peyceré, Horacio Corti o Marcelo Damiani publicados en esta misma editorial.

19 La siguiente novela de Ratto, Nudos (2008) insiste con la premisa formal del diálogo, aunque cobran algo más de visibilidad ciertos monólogos en el estilo de La traición de Rita Hayworth, como es el caso del monólogo de Chiro contemplando a la niña retrasada Marisa ("Ah, la Marisa siempre calladita, sentada ahí en esa silla inmunda, al sol como en un trono la reina que no dice nunca nada, con esa cara redonda y el pelo largo y las manos blandas sobre las piernas blandas. El culo de la Marisa debe ser gordo, blancos los cachetes blandos y rosa me la imagino por abajo que me la quiero coger, de rosa y tibia y mojada que debe ser [...] Voy a venir, Marisa, un día te voy a venir a tocar y no vas a gritar nada de nada y vas a hablar y te voy a enseñar a decir mi nombre [...]", 17-8) que remeda la entonación y el ritmo del capítulo de Cobito ("La gorda, dientuda, lavandera de mierda, gorda peronista del carajo, gorda mía, vení que estoy solo, todo el parque del colegio está abandonado hoy domingo, yo le doy charla al celador y vos te metés por la puertita de la verja y me esperás despanzurrada detrás de las casuarinas [...]", Puig 200-201). Una vez más, lo que eran innovaciones formales cuatro décadas atrás aquí aparecen adaptadas en beneficio de la legibilidad del mensaje. Se trata de simulacros de experimentación o bien de una reutilización de lo experimental que por eso mismo deja de serlo. El habla de los personajes, que solo por momentos logra transmitir la peculiaridad de sus personalidades termina resultando uniforme, con tendencia a repetir, desde la sintaxis de la oralidad, los mismos matices en todos los casos. ${ }^{2}$ Esta vez el registro narrativo se amplía para contar varias historias contenidas por la unidad de lugar (la ciudad de Tandil), en una atmósfera que remite vagamente a Cicatrices de Saer. Se puede considerar a Nudos como una novela de las buenas intenciones, donde se verifican pequeños triunfos morales que oponen su resistencia a la maldad voluntaria o involuntaria del mundo. En este caso el mal queda a cargo de un grupo de chicos de la villa a la que pertenece Chiro y que protagonizan el momento más violento de la novela, el asalto a una jubilada. La mirada de Roxana, asistente social que conoce a Chiro y a otros chicos marginados como él, es la que equilibra la polaridad al presentar a estos chicos como víctimas de sus circunstancias y no (solo) como monstruos violentos. Roxana a su vez, sin que nada lo justifique dentro de la lógica causal de la narración, busca compulsivamente la compañía de un ex combatiente de Malvinas que ha perdido una pierna y que se siente "siempre fuera de sitio" (87).

Como en la anterior novela, se produce una acumulación de recursos metafóricos que amenazan con lastrar el efecto general, que en buena medida descansa una vez más en la construcción de los personajes : hay demasiados perros y tullidos, en medio de los cuales otros personajes quedan flotando sin convicción, como el hombre casado que prostituye a chicos villeros o el contador que se suicida. La novela parece alargada, los recursos del diálogo se vuelven repetitivos al descansar en torno a pocos expedientes formales : abuso de los puntos suspensivos como réplica muda del diálogo ("- $¿$ Está bueno el mate ?/ Buenísimo./ -.../ -.../ -Señora, $i$ a usted le gusta hacer esos papeles ?", 19); uso 
indiscriminado de malas palabras, etc. El resultado es una novela que se limita a repetir los logros previos en una narración amplificada por más personajes y sus puntos de vista. Podría decirse que, hasta aquí, la autora ofreció una variación a primera vista enjundiosa aunque vacua de lo que fuera su presentación en el campo literario, buscando afianzar las características ya visibles en aquel primer título y por consiguiente subrayando las marcas de una escritura personal, vale decir, de un estilo.

Trasfondo (2012) es un texto pensado para aparecer -y aparecido, en efecto, con una etiqueta rectangular en la tapa que hace referencia a los treinta años del desembarco- en ocasión del aniversario de la guerra de las Malvinas y, como tal, se puede decir que tiene una motivación extra-artística. Por consiguiente, los aspectos destinados a garantizar la continuidad del proyecto novelístico de Ratto están ausentes: todo indicaba que esta novela debía ser más larga que las dos anteriores (según la lógica acumulativa exhibida previamente), y sin embargo es la más breve. Si dejamos a un lado la etiqueta, su título no permite a simple vista hacerse una idea del todo clara de lo que ofrece, y en tal sentido no participa de las características de un producto comercial evidente. Sin embargo, aquí el producto importa un poco más que el autor; aunque Trasfondo no se presenta como una unidad aislada sino como parte de una obra, de un determinado proyecto novelístico respaldado por la unidad que le da su publicación en un mismo sello editorial, se puede pensar que más que apelar a lectores que leyeron algún título previo de Ratto, se dirige especialmente a aquellos interesados en la guerra de Malvinas; de otro modo el sticker o faja hubiera anunciado "la nueva novela de Patricia Ratto" como el factor más significativo de esta novedad editorial.

El tema de Malvinas no es en nuestra autora un factor completamente exótico si pensamos en la progresión temática "dictadura" en Pequeños hombres blancos y "ex combatiente de Malvinas" en Nudos. No deja de ser significativo, dentro de la estética de la autora, que el punto de vista elegido en Trasfondo para abordar la guerra sea el de un submarino, es decir algo que no se deja ver, donde no pasan muchas cosas y donde lo que importa es la progresiva atmósfera de desaliento que invade a los personajes. El hallazgo más evidente es aquí el punto de vista de esta epopeya negativa : el de un suboficial que narra con estupefacción cómo a medida que son necesarios los distintos aparatos y armas del submarino en el que navegan, estos se revelan inútiles o inoperables. El diálogo laxo, por momentos insustancial, ha sido desplazado por un monólogo ajustado ; la efusividad pintoresca de los juramentos y demás expresiones coloquiales reducida solo a lo esencial, y en general la tendencia de la autora a tener en cuenta la regla de las unidades, aquí extremada, redunda en un efecto de intensidad que compensa la ausencia de sus heroínas bienintencionadas y carismáticas.

La novela se entrega a una reflexión soslayada, algo intrigante en su rechazo a toda filiación literaria explícita, a partir de la lectura, por parte del narrador, del relato "La madriguera" [Der Bau] de Kafka, ${ }^{3}$ que invita al lector a asociar las estrategias del innominado animal kafkiano a la absurda gesta a la que se ven obligados los tripulantes de un submarino donde, llegado el momento, nada funciona como debe funcionar. La presencia de Kafka vincula esta novela con ciertos procedimientos de la alegoría (modalidad que tiene mucho que ver con un género que anticipa al folletín decimonónico y a ciertos best-sellers: el romance -Frye 1976-) aunque no todo es sugerencia ni sobreentendido si nos atenemos a lo que plantea el propio narrador a pocas páginas de comenzado el relato : "Quizá todos seamos personajes de una historieta ridícula" (22), o al 
pasaje de la Biblia que lee uno de los tripulantes y que demasiado previsiblemente se refiere al episodio de Jonas y la ballena (43).

Además de tratarse de un texto pensado para aparecer en una ocasión puntual, debe señalarse una elección por la verosimilitud, asociada a la "investigación" del caso, que aparece en el despliegue de vocabulario técnico ("control tiro", "bomba de achique", "manifold superior"), muy distinta a la de otros submarinos literarios, pongamos por caso el de Juan Emar, que se desplaza por debajo de los continentes ("El vicio del alcohol", Diez ); esa opción por la verosimilitud es necesaria, junto con la coherencia psicológica de los personajes, para garantizar la "legibilidad" de la propuesta. Ya en el ámbito de lo extraliterario, la autora afirmó haber entrevistado a los distintos protagonistas del episodio real, con las dificultades añadidas del recelo de algunos militares a encontrarse con una versión que los desacreditara. En tal sentido, no se trata de un texto conformista ni intenta hacer pasar por un triunfo lo que fue un fracaso, como ocurre a menudo en las ficciones compensatorias que el best-seller heredó del folletín decimonónico (Gramsci 1998).

La estrategia consiste, como se puede comprobar entonces, en aplicar algunos aspectos o técnicas de las ficciones más comerciales, principalmente el uso de datos de la realidad antes que la pura imaginación, renunciando en el intento a los elementos de una poética propia que se definía por puntos de vista femeninos, el protagonismo de los sentimientos, las alternativas éticas de los personajes, todo ello dentro de un modelo de enunciación de clara matriz puiguiana y un modelo de enunciado que remite a los primeros títulos de Saer, es decir, dos de los proyectos novelísticos más significativos (y opuestos entre sí) de la segunda mitad del siglo xx en Argentina .

Se constata pues, en un sector del mercado editorial de habla hispana, una forma intermedia que, sin aplicar las características del best-seller puro y duro, responde a demandas algo más versátiles que la de un consumo que requiere cantidad a expensas de la calidad. En un escenario en el que grandes grupos compran sellos grandes o pequeños con tendencia a uniformar u homogeneizar la producción y en concreto como forma de eliminar la competencia, Adriana Hidalgo sobrevive a la formidable crisis y va consolidando en un lapso de quince años un catálogo en donde convive el criterio artístico, estético o académico con un criterio comercial paulatino que es necesario desplegar aunque sea mínimamente como estrategia de supervivencia. La obra de Ratto aparece como una emergencia de esta tendencia, sobre todo al responder a una demanda puntual en su última novela, en la que sacrifica las características que definían el estilo de su obra y en la que la búsqueda personal es reemplazada por una consigna coyuntural. Esto da como resultado algo paradójico : un texto que, en su alejamiento de la genealogía novelesca más evidente (Puig, Saer) y en su renuncia a motivos más personales (personajes femeninos, imperio del sentimiento) gana en una discursividad más concentrada y deja atrás cierta tendencia al estereotipo.

Mientras que un mercado como el español se acerca más al formato clásico del best-seller en novelas que pretenden no ser comerciales, según se comprueba en el citado ejemplo de la editorial Salamandra, el mercado argentino ofrece alternativas que se apartan más aún del modelo clásico de novela comercial : ambigüedad textual y paratextual, brevedad (y consecuente calidad en la escritura) y presencia reducida del "saber útil" en el nivel de lo veredictivo. chico o de menor demanda, como el mercado argentino del libro en comparación con el 
mercado estadounidense o español, condiciona menos las características intrínsecas del producto, pero que al mismo tiempo es capaz de desviar un proyecto novelístico "literario" sin destruirlo del todo. Eso es al menos lo que permite deducir la obra de la autora estudiada en el marco de transición de una editorial chica a una editorial mediana.

\section{BIBLIOGRAFÍA}

\section{Bibliografía}

Aira, César. "Best-seller y literatura". ABC Cultural. 1 abr. 2000 : 7-8.

Aznarez, Juan. “Un camino poco explorado en el negocio de los libros”. La Nación. 20 dic. 1999 : sección $2^{\mathrm{a}}: 8$.

Carricaburo, Norma. "La sintaxis de la oralidad", Litterae. Revista del Idioma español 29-30 (2005) : 163-184.

Chefjec, Sergio. “Sísifo en Buenos Aires”, Punto de vista 72 (2002) : 26-31.

Frye, Northrop. La escritura profana. Caracas : Monte Ávila, 1976.

Gandolfo, Elvio E. “Prólogo” en Ricardo Colautti, La conspiración de los porteros y otras novelas. Buenos Aires : Mansalva, 2007.

Gramsci, Antonio. "Literatura popular", en Literatura y vida nacional. Cuadernos de la cárcel 4. México : Juan Pablos, 1998.

Molina, Daniel. "Nuestros libros extranjeros”. Clarín. 16 mar. 2002 : Cultura y Nación : 2.

Pérez, Ana Laura. "El mercado de los originales". Clarín. 20 jul. 2002 : Cultura y Nación : 2.

Pomeraniec, Hinde. "Después de treinta años fue promulgada la Ley del Libro". Clarín. 26 jul. $2001: 37$

Premat, Julio. Héroes sin atributos. Figuras de autor en la literatura argentina. Buenos Aires : FCE, 2009.

Puig, Manuel. La traición de Rita Hayworth. Barcelona : Seix Barral, 1987.

Ratto, Patricia. Pequeños hombres blancos. Buenos Aires : Adriana Hidalgo, 2006.

Ratto, Patricia. Nudos. Buenos Aires : Adriana Hidalgo, 2008.

Ratto, Patricia. Trasfondo. Buenos Aires : Adriana Hidalgo, 2012.

Sarraute, Nathalie. “Conversation et sous-conversation”, L’ère du soupçon. Paris : Gallimard, 1957.

\section{NOTAS}

1. Las editoriales pequeñas, sobre todo en sus inicios, suelen depender para los textos extranjeros de los programas de ayuda o difusión cultural de los respectivos países, que pueden llegar a financiar la producción completa (o bien la mitad) de un determinado título. Esto a veces da como resultado cierta uniformidad en el catálogo y una perspectiva acaso demasiado oficial de la 
cultura de que se trate, aunque a la vez constituyen la única oportunidad de dar a conocer textos que de otro modo no llegarían al mercado de habla hispana.

2. Los elementos que articulan la sintaxis de la oralidad son: parataxis y yuxtaposición; flexibilidad en la concordancia; orden oracional ; empleo de palabras generales; perífrasis y circunloquios ; redundancia de la información ; nexos inespecíficos ; deícticos ; coordinación intensiva; uso preposicional laxo; frases hechas, muletillas, conectores interenunciativos y marcadores de modalidad. Cf. Carricaburo 2005.

3. Aunque el relato de Kafka es citado y glosado a lo largo de todo el texto de Trasfondo, en ningún momento se especifica su autoría o su título. Muy en la tradición de los escritores argentinos, Ratto comparte la obsesión local de mezclar lo "groncho y lo académico" (Gandolfo 8), en este caso escamoteando con énfasis toda credencial literaria que pueda considerarse "intelectualoide" y sin embargo utilizando sistemáticamente el hipotexto como clave interpretativa de su propio argumento hasta la última página. El narrador lo menciona como "un libro que encontré por ahí, viejo, amarillo, le falta la tapa" (55).

\section{RESÚMENES}

Adriana Hidalgo Editora es una muestra, entre otras, de cómo las editoriales pequeñas atraviesan procesos de desarrollo y transformación, y de que hay una categoría intermedia entre la editorial "chica y prestigiosa" y la megaeditorial. Las tres novelas de Patricia Ratto publicadas por este sello se presentan como demostración textual de dichos procesos.

Le cas de la maison d'édition argentine Adriana Hidalgo Editora est un témoignage, entre autres, de comment les petites maisons d'édition éprouvent des processus de développement et de transformation. Ce cas montre aussi qu'il existe une catégorie intermédiaire entre la maison d'édition "petite et prestigieuse" et la méga-entreprise. Les trois romans de Patricia Ratto publiés par cette maison se présentent comme démonstration textuelle de ces processus.

Adriana Hidalgo Editora is an example, among others, of how a small publishing house experiences processes of development and transformation. It shows also that there is an intermediate category between the "small and prestigious" publishing house and the big one. The three novels of Patricia Ratto published by Adriana Hidalgo appear as a textual demonstration of such processes.

\section{ÍNDICE}

Mots-clés: maison d'édition, Patricia Ratto, best-seller

Palabras claves: editorial, Patricia Ratto, literatura comercial

Keywords: publishing house, Patricia Ratto, best-seller 
AUTOR

MARIANO GARCÍA

Conicet/UCA 